\title{
Índice de satisfação da limpeza urbana na zona urbana de Pau dos Ferros/RN
}

\author{
Talita Tássia da Costa ${ }^{1 \star(D)}$, Joel Medeiros Bezerra ${ }^{2}$ (D), Bruna Monallize Duarte Moura ${ }^{2}$ (D), Alana \\ Ticiane Alves do Rêgo ${ }^{1}$ (D), Rafael Silva de Souza ${ }^{1}$ (D), Antonio Batista de Queiroz Júnior ${ }^{1}$ (D), Francisco \\ Soares Roque ${ }^{2}$ (D), Samilly Brito Nobre ${ }^{2}$ (D), Helves Clerverton Guerra Costa ${ }^{2}$ (D)

\footnotetext{
${ }^{1}$ Universidade do Estado do Rio Grande do Norte, Rua Sinhazinha Wanderley, 871 - Centro, Açu - RN, 59650-000

${ }^{2}$ Universidade Federal Rural do Semiárido, Rua Francisco Mota Bairro, 572 - Pres. Costa e Silva, Mossoró - RN, $59625-$ 900

* Autor para correspondência: talitatcosta@hotmail.com
}

Recebido em 23 de maio de 2020.

Aceito em 27 de setembro de 2020.

Publicado em 30 de setembro de 2020.

Resumo - O processo de urbanização tem se intensificado devido o crescimento econômico e inserção social que propiciaram a ocupação desenfreada e não planejada. Com o aumento no consumo e na geração dos resíduos sólidos se estabeleceu um cenário preocupante quanto sua destinação e disposição. Diante esse contexto, o presente trabalho propõe a análise do Índice de Satisfação de Limpeza Urbana como uma ferramenta norteadora para gerenciamento deste serviço no município de Pau dos Ferros- RN. Aplicou-se 398 questionários em 17 bairros diferentes, em uma pesquisa de opinião quanto à frequência de coleta e limpeza urbana. Estipulou-se pesos nas alternativas de acordo com a relevância e com o uso de média ponderada e delimitou-se o índice geral e por bairro. Os resultados apontam que 70,6 \% dos bairros possuem o nível baixo de satisfação e 29,4 \% classificaram como média satisfação, onde se destacam com maior e menor valor, respectivamente, João Catingueira e Beira Rio. O índice de satisfação demonstrou que o sistema de limpeza urbana se apresenta predominantemente com indicadores que variam entre médio e baixo desempenho. Esse cenário difere das principais zonas urbanas brasileira, onde áreas mais centrais acabam sendo mais assistidas pelo poder público, o que não foi possível verificar no município de estudo.

Palavras-chave: Resíduos Sólidos. Salubridade Ambiental. Saneamento Básico.

\section{Satisfaction index of the urban cleaning system in the urban area of Pau dos Ferros / RN}

Abstract - The process of urbanization has increased due to the economic and social evolutionary process
that provided uncontrolled and unplanned occupation of lands. With the increase in consumption and
generation of solid waste, it established a worrying scenario regarding its destination and disposal. Facing
this context, the present work proposes the analysis of the Urban Cleaning Satisfaction Index as a guiding
tool for managing waste disposal services in the city of Pau dos Ferros-RN. Thus, 398 questionnaires were
applied in 17 different neighborhoods. Regarding the analysis of the frequency of collection and urban
cleaning, to each alternative it was stipulated a weight according to its relevance and through the weighted
average of the answers the general index and the index by neighborhood was determined. The results
show that $70.6 \%$ of the neighborhoods had a "low level" of satisfaction and $29.4 \%$ classified it as "average"
satisfaction. The neighborhoods that stood out with the highest and lowest index were, respectively, João 
Catingueira and São Geraldo. Therefore, in the light of the population's satisfaction, it can be seen that the urban cleaning system is presented predominantly with indicators that vary between medium and low performance, showing a spatialization that differs from the main Brazilian urban areas, in which the most central areas end up being more assisted by public authorities, which was not verified in the municipality to which this study refers.

Keywords: Solid Waste. Environmental Health. Basic Sanitation.

\section{Índice de satisfacción de la limpieza urbana en el área urbana de Pau dos Ferros / RN}

Resumen - El proceso de urbanización se ha intensificado debido a la creciente evolución económica e inserción social que condujo a una ocupación desenfrenada y no planificada. Con el aumento en el consumo y la generación de residuos sólidos, se estableció un escenario preocupante con respecto a su destino y disposición. Dado este contexto, el presente trabajo propone el análisis del Índice de Satisfacción de Limpieza Urbana como una herramienta guía para gestionar este servicio en la ciudad de Pau dos Ferros-RN. Por lo tanto, se aplicaron 398 cuestionarios en 17 vecindarios diferentes, con respecto al análisis de la frecuencia de recolección y limpieza urbana, se estipularon pesos en las alternativas de acuerdo con la relevancia y el uso del promedio ponderado y se definió el índice general y por barrio. Los resultados indican que el 70.6\% de los barrios tienen un bajo nivel de satisfacción y el 29.4\% lo clasificó como satisfacción mediana, donde se destacaron con mayor y menor valor, respectivamente, João Catingueira y Beira Rio. El índice de satisfacción demostró que el sistema de limpieza urbana se presenta predominantemente con indicadores que varían entre mediano y bajo desempeño. Este escenario es diferente de las principales zonas urbanas brasileñas, donde las áreas más céntricas resultan más asistidas por el poder público, lo que no se puede verificar en el municipio del estudio.

Palabras Clave: Residuos Sólidos. Salud Ambiental. Saneamiento básico.

\section{Introdução}

O crescimento espacial, econômico, demográfico e as transformações do ambiente no decorrer do tempo proporcionaram o surgimento de uma intensa urbanização, atrelada com o uso dos recursos naturais em grandes proporções e consequentemente uma maior geração de resíduos sólidos no mundo. Diante desse panorama, surge a problemática de como coletar, transportar, acondicionar, descartar, destinar e dispor de forma adequada os resíduos para assim minimizar os impactos no meio (Araújo e Pimentel 2015; Ramos et al. 2017).

Voltado à promoção do bem-estar e equilíbrio entre as condições sanitárias do ambiente e a saúde da população surge o saneamento básico, o qual compreende os eixos de abastecimento de água, esgotamento sanitário, drenagem de águas pluviais e gerenciamento de resíduos sólidos, no qual consistem em uma ferramenta que visa garantir a salubridade ambiental para a população, ou seja, proporcionar qualidade de vida e saúde através da disponibilização de serviços estruturais, ambientais, sociais e econômicos (Marchi 2015).

O gerenciamento adequado de resíduos sólidos tem ganhado força desde 2010 no Brasil, quando foi instituída a Política Nacional de Resíduos Sólidos (PNRS), lei no 12.305 de 2010. Entretanto, algumas regiões brasileiras tiveram avanços lentos, como é o caso da região Nordeste, sendo essa 
caracterizada por deter um grande número de municípios e baixos índices de eficiência na área de saneamento ambiental (Silva et al. 2018).

Segundo Godoy (2016), o serviço de limpeza envolve diversos serviços naturais para a organização da zona urbana e rural, entre estes destaca-se a varrição de vias públicas, podas e a coleta e transporte dos resíduos. Vale salientar que este setor possui grandes entraves na execução das atividades devido a deficiência de uma gestão direcionada no fornecimento periódico, com qualidade e em toda área de abrangência (Texeira et al. 2016).

De acordo com a Abrelpe (2019), no Brasil são geradas 79 milhões de toneladas resíduos/ano, sendo que a região Nordeste detém $22 \%$ deste valor, mas vale salientar que mesmo com investimento de $\mathrm{R} \$ 28,1$ bilhões/ano na prestação deste serviço, deixa-se de coletar anualmente cerca de $8 \%$ deste quantitativo no país. Além destes, tem-se em muitos municípios brasileiros a disposição e destinação inapropriada dos Resíduos Sólidos Urbanos (RSU) ocasionando danos diretos no setor econômico das cidades, desde o comprometimento do planejamento urbano, desvalorização imobiliária, comprometimento paisagístico urbano, problemas a drenagem urbana, proliferação de vetores de patógenos, além das perdas no aproveitamento econômico desses materiais na reciclagem (Galdino e Malysz 2016).

Dessa forma, com o objetivo de qualificar um dos componentes do saneamento básico, o Índice de Satisfação à Limpeza Urbana (ISLU) foi desenvolvido ao considerar a satisfação dos usuários em relação aos serviços prestados (Menezes Filho e Rodrigues 2017). Originalmente, o ISG foi concebido para aplicabilidade de forma complementar ao Indicador de Salubridade Ambiental (ISA), sendo este último, um modelo de indicador amplamente utilizado no Brasil desenvolvido pelo Conselho Estadual de Saneamento em São Paulo (Menezes Filho e Rodrigues 2017; Teixeira, Filho e Santiago 2018).

Segundo Menezes Filho e Rodrigues (2017), a ideia de complementar o emprego do ISA com o ISG surgiu devido a lacuna deixada pelo ISA ao não considerar a satisfação dos usuários na qualificação técnica do saneamento ambiental. Neste cenário, o autor argumenta que a participação popular nas questões de saneamento está prevista nas diretrizes nacionais para o saneamento básico (Lei n $\left.{ }^{\circ} 11.445 / 2007\right)$, sendo os populares envolvidos com a fiscalização e a comunicação de problemas junto a Administração Pública (Menezes Filho e Rodrigues 2017).

O ISLU consiste numa análise da percepção da população assistida por serviços de limpeza urbana, como a varrição, coleta, destinação, reutilização, reciclagem, tratamento e outros serviços correlacionados com os resíduos sólidos urbanos em uma determinada localidade. Dessa forma, na perspectiva de suprir a lacuna que engloba a complexidade do sistema existente na PNRS, na qual dificulta o planejamento e a execução de ações específicas voltadas para a melhoria da qualidade dos serviços prestados, o ISLU surge com a possibilidade de contribuir para identificar os principais problemas no que diz respeito à gestão da limpeza urbana e na busca de soluções adequadas (SELUR, 2017). O presente trabalho propõe-se analisar a satisfação dos serviços de limpeza urbana disponibilizados a população da zona urbana de Pau dos Ferros/RN, para assim mensurar a eficiência dessa atividade na cidade e com isso propor ações mais efetivas em determinadas áreas de vulnerabilidade.

\section{Material e métodos}

\section{Área de estudo}

O estudo foi realizado no município de Pau dos Ferros/RN, no semiárido nordestino. De acordo com dados do Instituto Brasileiro de Geografia e Estatística (IBGE), o município possui uma área 
de $259,959 \mathrm{~km}^{2}$, que equivale a $0,52 \%$ do território estadual, e uma população estimada de 30.394 habitantes (IBGE 2019).

Devido à sua localização geográfica estratégica, Pau dos Ferros se tornou um importante centro econômico regional, no qual tem como principal atividade econômica, o comércio de bens e prestação de serviços, possibilitando a atração de uma quantidade expressiva de pessoas, especialmente das cidades circunvizinhas, movimentando a economia local e favorecendo o crescimento e desenvolvimento dessa cidade (Silva, Guerra, Dantas 2016; Paiva e Giesta 2019; Santana e Diniz 2019).

\section{Definição do tamanho da amostra}

O desenvolvimento da amostragem populacional do referido estudo se deu por meio da utilização dos dados fornecidos pelo escritório local da Companhia de Águas e Esgotos do Rio Grande do Norte (CAERN) em Pau dos Ferros. Esses dados são referentes ao número de ligações de água ativa da zona urbana do município, distribuídas por bairro no ano de 2018 (Figura 1).

Figura 1. Disposição dos bairros em estudo da zona urbana de Pau dos Ferros/RN.

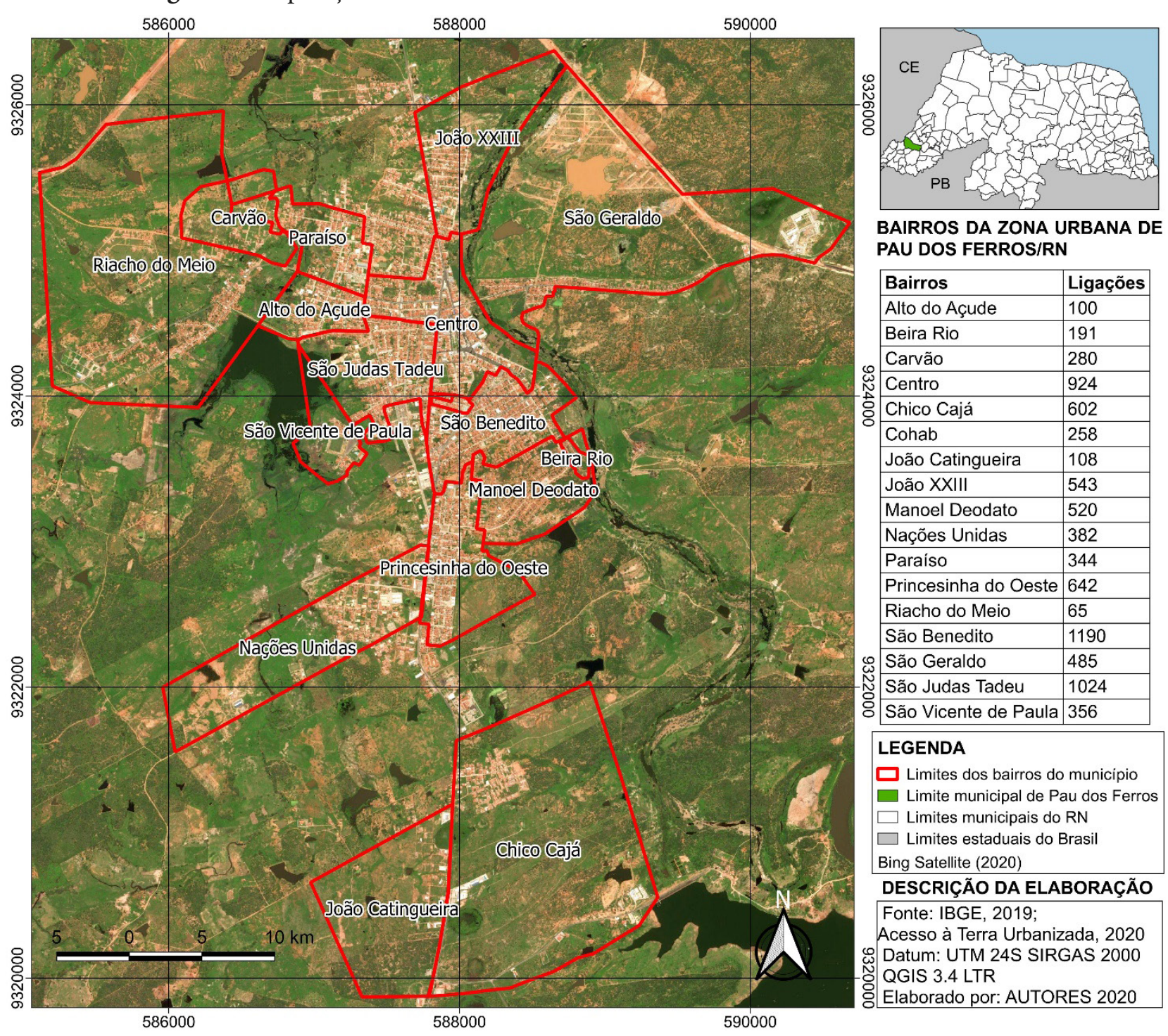


Para o cálculo da amostra desse estudo realizou-se conforme metodologia proposta por Martins (2008), na qual considera-se a variável nominal e a população finita, bem como utiliza-se um nível de confiança de $95 \%$ e proporção igual 0,50. Tendo em vista encontrar uma amostra representativa, obteve-se um valor mínimo equivalente a 367 questionários, conforme ao número de ligações ativas nos 17 bairros que compõe a zona urbana do município. Todavia, diante a acessibilidade da população ao responderem aos questionamentos realizados por formulário eletrônico, foram contabilizados 398 questionários ao final.

\section{Coleta e tratamento de dados}

Os questionários foram aplicados no período entre os meses de junho e julho de 2018, sendo realizadas visitas in loco e também através de formulário eletrônico, no qual era composto por perguntas objetivas e direcionadas à população residente nos 17 bairros que compõem a zona urbana de Pau dos Ferros/RN. A pesquisa realizada em campo, da qual procedeu-se por meio de uma seleção aleatória nos domicílios, teve como critério de escolha apenas os moradores locais interessados a responderem os questionamentos da pesquisa durante o período realizado para a coleta de dados. Dessa forma, os indivíduos não interessados, não residentes do município, bem como do respectivo bairro entrevistado não foram investigados.

Com os dados obtidos, esses foram agrupados em categorias por meio de análise das informações descritas e depois quantificados perante o nível de satisfação do serviço prestado. Para o tratamento dos dados utilizou-se de técnicas de estatística simples e plotagem dos dados em gráficos com o auxílio do software Microsoft Excel versão 2016.

\section{Índice de Satisfação da Limpeza Urbana (ISLU)}

O Índice de Satisfação à Limpeza Urbana (ISLU) foi desenvolvido com objetivo de qualificar um dos componentes do saneamento básico, considerando como critério para classificar a satisfação dos usuários em relação aos serviços prestados. A qualificação global da satisfação dos usuários com relação aos serviços públicos de saneamento, integrando o ISLU em sua estruturação, é estimada pelo Índice de Satisfação Geral (ISG) (Menezes Filho e Rodrigues 2017).

Buscou-se exemplificar o grau de satisfação da população quanto às ações relacionadas a coleta e disposição de resíduos em locais públicos. Conforme metodologia proposta por Menezes Filho e Rodrigues (2017), seu cálculo corresponde à média aritmética (Equação 1), entre as respostas de frequência de limpeza urbana $(\mathrm{F})$ e presença de resíduos sólidos em locais públicos (P).

$$
I S L U=\frac{(F+P)}{2}
$$

Sendo,

ISLU = Índice de satisfação à limpeza urbana;

$\mathrm{F}=$ Frequência da limpeza urbana;

$\mathrm{P}=$ Presença de resíduos sólidos em locais. 
A frequência da limpeza urbana $(\mathrm{F})$ corresponde a análise da média ponderada entre as respostas de alta satisfação (soma de muito satisfeita e satisfeita) dotada de peso 1 e a média (pouco satisfeito) com peso de 0,5 , conforme a Equação 2.

$$
F=\frac{R_{\text {alta }}(M S+S) * 1+R_{\text {média }}(P S) * 0,5}{R_{\text {total }}}
$$

Em que,

$\mathrm{R}_{\text {alta }}=$ Respostas com alto nível de satisfação, considerando alternativa muito satisfeita (MS) e satisfeita(S);

$\mathrm{R}_{\text {média }}=$ Respostas com médio nível de satisfação, considerando para isso alternativa pouco nível de satisfação (PS);

$\mathrm{R}_{\text {total }}=$ Soma de todas as respostas.

A presença de resíduos sólidos em locais públicos (P) é dada através da Equação 3.

$$
P=\frac{R_{\text {altaN }}}{R_{\text {total }}}
$$

Sendo,

$\mathrm{R}_{\text {altaN }}=$ Respostas com alternativa "não";

$\mathrm{R}_{\text {total }}=$ Soma de todas as respostas.

Assim, a classificação quanto à satisfação dos usuários em relação aos serviços de limpeza urbana prestados pelo município se deu conforme o valor do Índice de Satisfação Urbana (ISLU) registrado segundo a Tabela 1 .

Tabela 1. Classificação para o ISLU.

\begin{tabular}{cc}
\hline VALOR DO ISLU & CLASSIFICAÇÃO \\
\hline $0,00-0,39$ & Baixo \\
$0,40-0,69$ & Médio \\
$0,70-1,00$ & Alto \\
\hline
\end{tabular}

Fonte: Adaptado de Menezes Filho e Rodrigues (2017).

Posteriormente a classificação dos dados foram empregados os recursos do software QGIS 3.14 Ltr, possibilitando a espacialização dos dados mediante produção de carta temática, identificando a distribuição espacial da satisfação da limpeza urbana por bairros.

\section{Resultados e discussão}

Não foram verificados bairros que apresentam alta satisfação dos beneficiados com relação a limpeza urbana, havendo a predominância de bairros de baixa satisfação (70,6\%) (Figura 2). Os 
bairros de Carvão, João Catingueira, João XXIII, Manoel Deodato e Princesinha do Oeste, que juntos correspondem a $29,4 \%$ da zona urbana do município, foram classificados com média satisfação.

Figura 2. Índice de Satisfação de Limpeza Urbana dos bairros de Pau dos Ferros/RN.

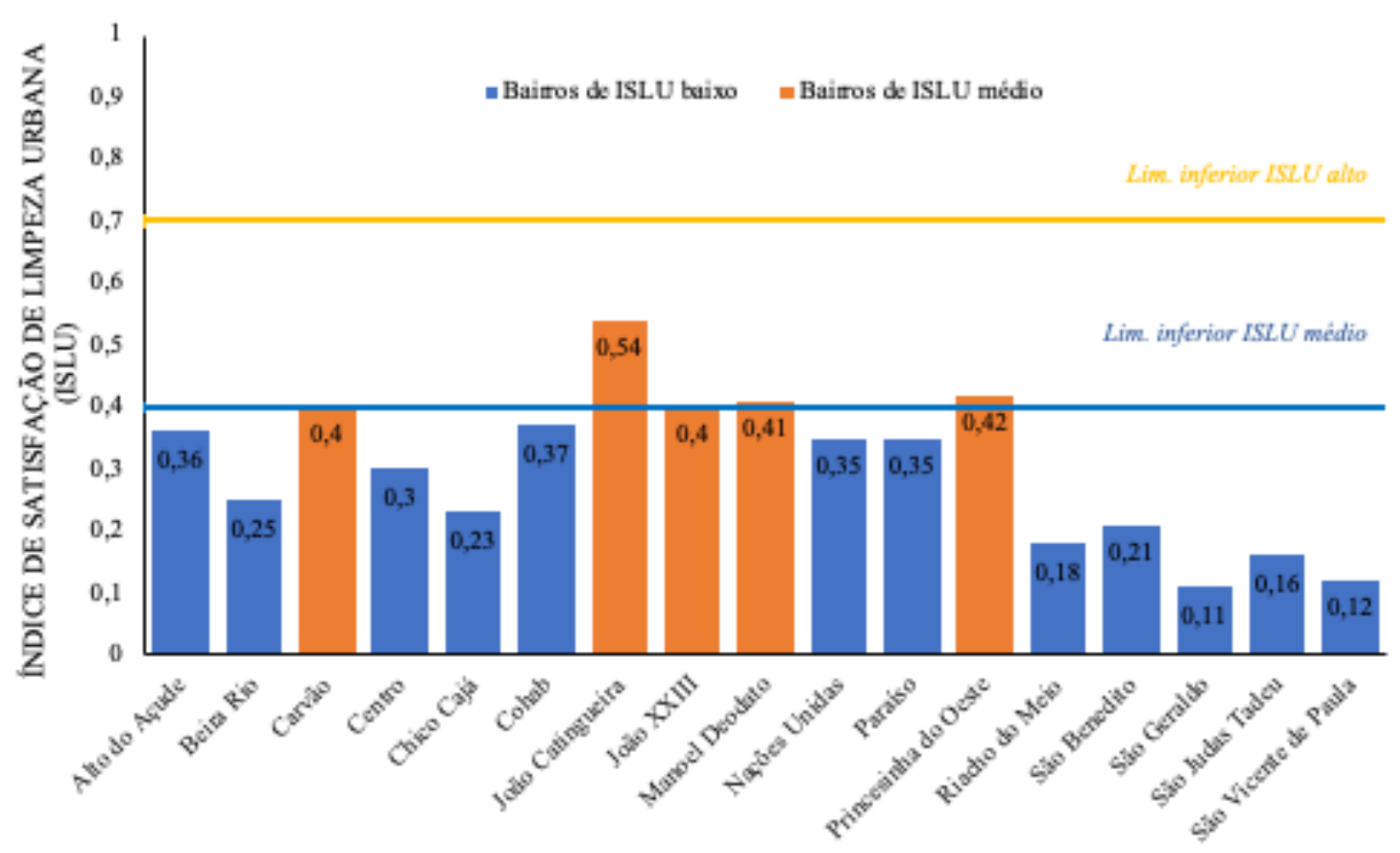

Destaca-se com menor índice (crítico) o bairro São Geraldo com 0,11. Esse resultado pode estar associado ao despejo de resíduos sólidos e formações de entulhos nas ruas, bem como localizar-se em uma região periférica como pouca cobertura de limpeza urbana. Existe diferenciação no grau de satisfação dos usuários entre os bairros que pode ser resultante de uma prestação de serviço não hegemonia segundo a percepção dos moradores (Figura 3). É interessante notar que dos cinco bairros com maiores ISLU, alguns possuem peculiaridades quanto as condições socioeconômicas encontradas. O bairro João Catingueira caracteriza-se por possuir um número reduzido de residências, 108 ligações ativas de acordo com a CAERN, tornando mais eficiente o serviço de coleta no bairro. O resultado encontrado no bairro Princesinha do Oeste, com segundo maior índice de satisfação, pode ser atribuído ao fato do mesmo possuir uma cobertura de saneamento onde todas as suas residências são ligadas ao sistema de abastecimento de água, energia elétrica e coleta de lixo, sendo 56,37\% das residências ligadas ao sistema de esgotos, refletindo também na limpeza urbana do bairro (Bezerra e Lima, 2011). Já o bairro Manoel Deodato, no qual é considerado periférico e de baixo índice de escolaridade (Maia, 2016), tal resultado pode ser relacionado a percepção ambiental da população, em que o fato de haver coleta já torna o serviço suficiente, no qual Mucelin e Bellini (2008) explica que é intrinsecamente relacionado às crenças e aos hábitos locais instituídos. 
Figura 3. Distribuição espacial do Índice de Satisfação de Limpeza Urbana dos bairros de Pau dos Ferros/

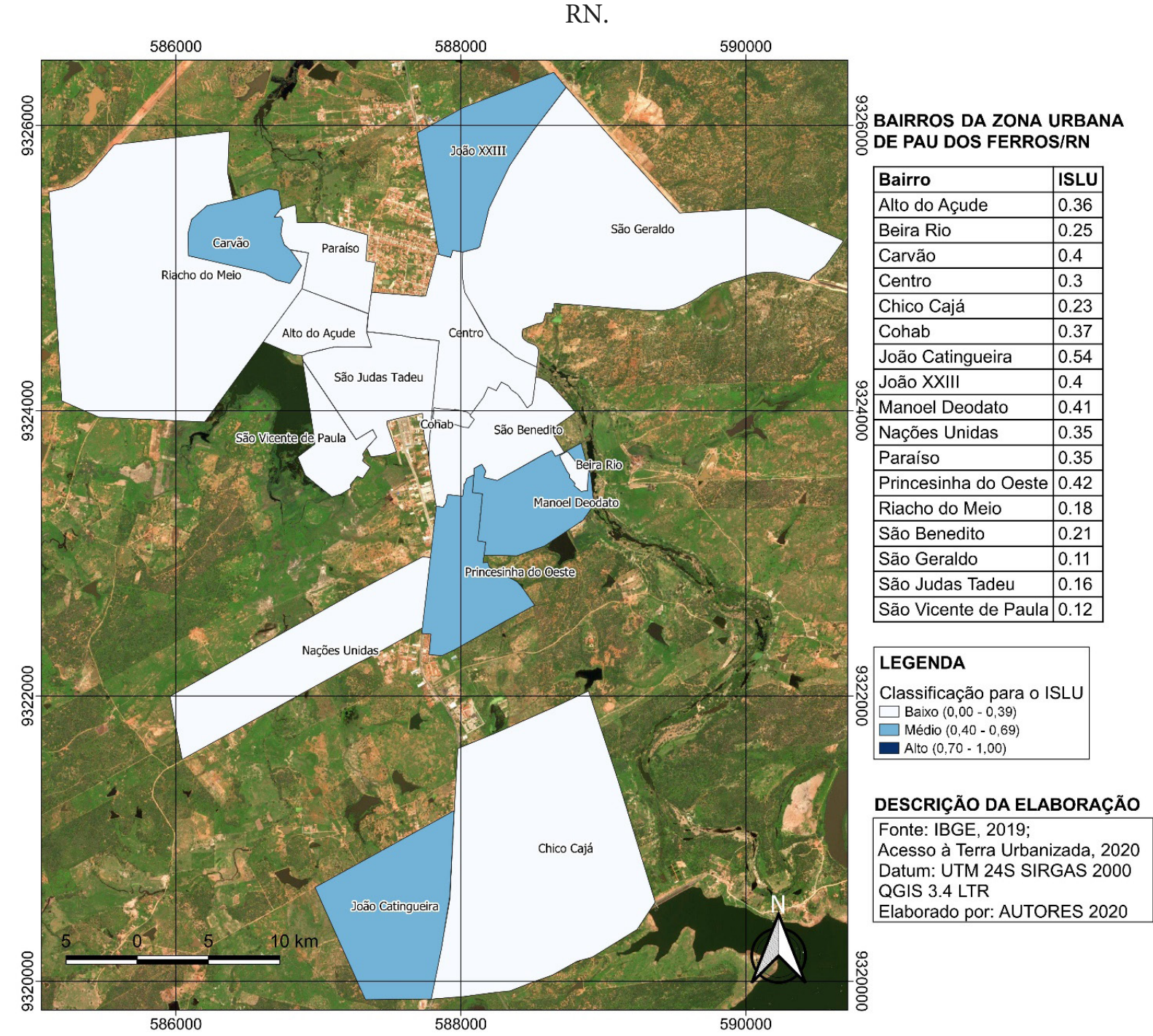

A média do ISLU calculado para o município foi de 0,29 , indicando um baixo índice na análise macroespacial. Esse resultado desfavorável pode ser explicado de acordo com levantamentos realizados por Silva e Medeiros (2011), ao constatarem que o município dispõe de poucos profissionais (52 garis) para as funções simples desde capinação, poda de árvores e varrição, e que os mesmos se concentram na execução de serviços apenas em áreas centrais.

De forma geral, a qualificação do ISLU expresso na Figura 2 e 3 é crítico, expondo o descontentamento da população em relação aos serviços público de limpeza urbana em Pau dos Ferros. Os resultados verificados por Menezes Filho e Rodrigues (2017) para o município de Rio de Paranaíba-MG, indicam apenas dois bairros do município classificados na categoria de baixa satisfação (13\%), enquanto em Pau dos Ferros esse valor é de 12 bairros (70,6\%).

A discrepância entre valores apresentados por Menezes Filho e Rodrigues (2017) e o de Pau dos Ferros se estende também para comparação entre os melhores e piores valores de satisfação entre bairros das duas cidades. Enquanto o bairro Olhos d'água apresentou ISLU igual a 1,0, em Rio de Paranaíba, o bairro que apresentou melhor valor de satisfação em Pau dos Ferros foi João Catingueira com 0,54 , uma diferença de $48 \%$ de satisfação entre os resultados. Para o pior cenário 
de comparação, o bairro Progresso obteve um ISLU pouco abaixo de 0,3 em Rio de Paranaíba, e o bairro São Geraldo com 0,1 em Pau dos Ferros. Ressalta-se que são municípios de pequeno porte, com população inferior a 50 mil habitantes e PIB per capita abaixo de R \$50.000,00 (IBGE, 2020).

Os cenários distintos podem ser explicados pelodado apresentado no Sistema Nacional de Informações sobre Saneamento (SNIS), no qual aponta que no Brasil 44,7\% da população brasileira encontra-se em situação de déficit de atendimento do serviço regular de coleta de Resíduos Domiciliares (RD), onde a região Nordeste concentra 2,9\% da população, sendo essa a maior taxa da população urbana do Brasil não atendida pelo serviço comparada às outras regiões no país (SNIS 2018).

Os três melhores resultados em relação à frequência da coleta de resíduos promovida pelo sistema público municipal foram verificados nos bairros João Catingueira, Manoel Deodato e Princesinha do Oeste, todos classificados com ISLU médio (Figura 4). Bairros como Centro e São Benedito apresentaram boa abrangência da coleta semanal de resíduos, porém foram caracterizados com baixa satisfação pelos beneficiários. Estes dois bairros se destacam pela presença de atividades de comércio, concentrando maior fluxo de habitantes do município e da região do entrono, resultando em maior presença de resíduos sólidos em locais públicos de suas áreas e influenciando na redução do ISLU. Vale ressaltar que a economia de Pau dos Ferros é centrada no setor terciário, desempenhando papel de importância regional pelo seu comércio (Dantas 2014).

Figura 4. População assistida por coleta comum três vezes por semana do munícipio de Pau dos Ferros/RN.




Os bairros de Carvão e João XXIII, apesar de estarem entre os bairros com melhor qualificação do ISLU em Pau dos Ferros, apresentaram resultados medianos quanto a abrangência da coleta semanal. O Carvão é considerado um bairro periférico, que surgiu e vem se desenvolvendo recentemente, apresentando deficiências de infraestrutura como acessibilidade comprometidas em algumas de suas vias (Figura 5a), fato que podem dificultar a movimentação dos caminhões de coleta. Este fator pode influenciar a abrangência do serviço de coleta no bairro e, consequentemente, a percepção dos moradores quanto a frequência do serviço de coleta. Já o bairro João XXIII é cortado pela Rodovia BR 405, apresentando suas ruas como ramificações a partir desse acesso principal. A frequência da coleta de resíduos no bairro pode ser prejudicada por apresentar sua via principal com alto volume de trânsito e empreendimentos de comércio que dificultam o tráfego dos automóveis. Também foi verificado concentração de resíduos sólidos lançados a partir dos carros em circulação ao longo da BR 405 no bairro (Figura 5b).

Figura 5. A) Via com acessibilidade comprometida no bairro Carvão em Pau dos Ferros/RN. B) Resíduos dispostos ao longo da BR 405 no Bairro João XXIII em Pau dos Ferros/RN.

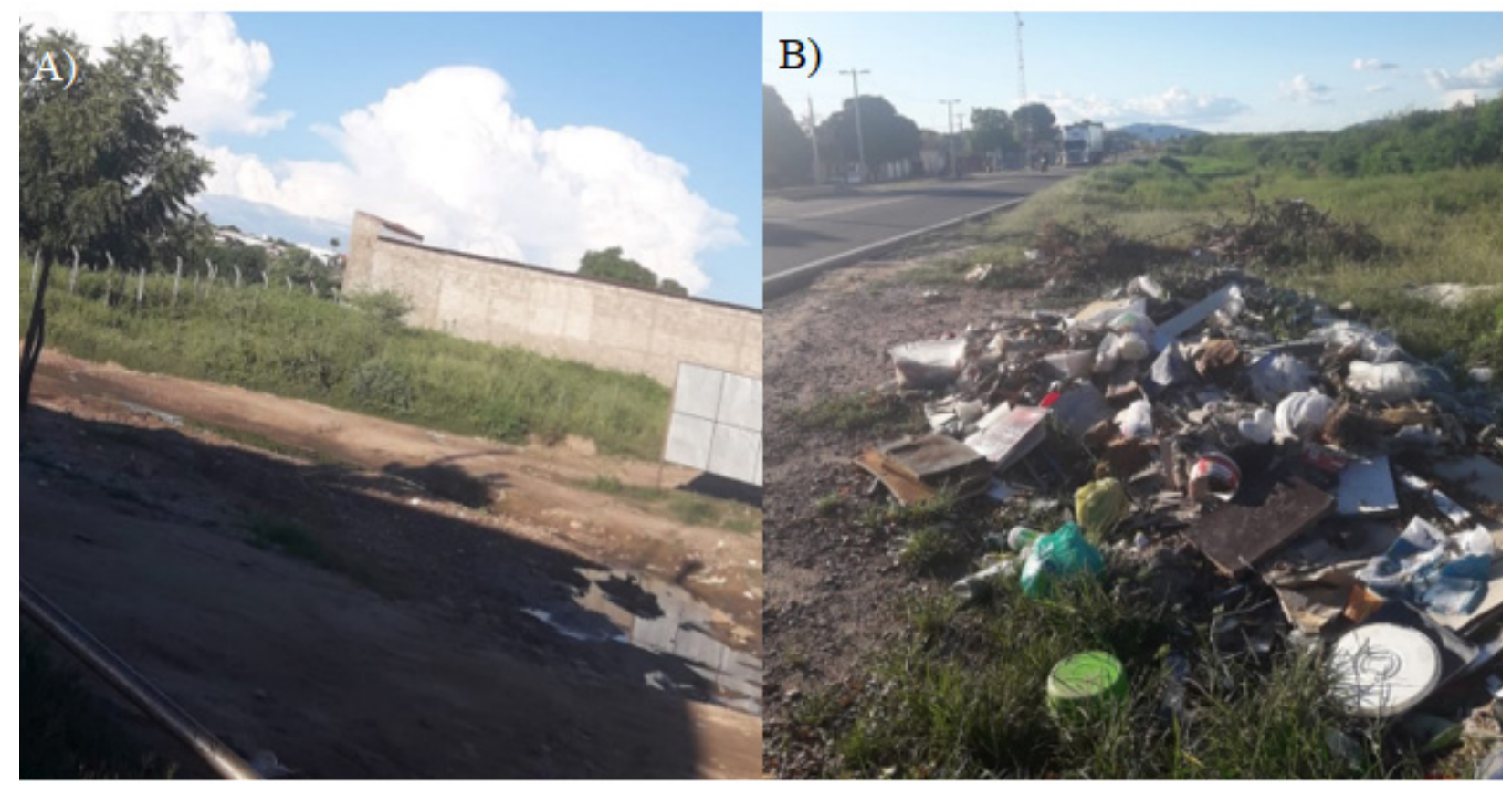

Para a manutenção dos serviços de coleta, manter a frequência de dias e horários predeterminados para cada rota é fundamental para a adesão da população ao descarte correto dos resíduos, desta forma, estes materiais estarão disponíveis para coleta apenas nos dias previstos pelo cronograma, minimizando o acúmulo de resíduos nos locais públicos (Monteiro 2018). Segundo o IBAM (2001), a frequência da coleta de resíduos recomendada no Brasil não deve exceder o período de uma semana, isto se deve às condições climáticas do país que favorecem a decomposição dos resíduos, sobretudo da fração orgânica. Após este período, pode haver a proliferação de moscas e o aparecimento de mau cheiro, além da atratividade de outros insetos e animais.

A avaliação das condições da limpeza urbana, apesar de ser apenas um dos múltiplos indicadores, pode ser considerada como um indicativo da qualidade ambiental urbana (Barbosa e Moura, 2020). Neste caso, o correto funcionamento dos serviços prestados de limpeza urbana deve sempre contar 
com o apoio e empenho da população beneficiada, para tanto, deve ser natural o envolvimento dos populares no levantamento de indicadores sobre as condições de limpeza urbana. Com esta perspectiva, justificasse a aplicabilidade do ISLU, que considera a satisfação dos beneficiários dos serviços de limpeza urbana. Dessa forma, a qualificação do ISLU busca contribuir no enfrentamento aos problemas dos serviços de limpeza urbana com o objetivo de melhorar as condições da qualidade ambiental nas cidades.

É importante ressaltar que, durante o desenvolvimento da pesquisa, observou-se que os entrevistados, em sua maioria, não sabiam distinguir limpeza urbana dos demais eixos do saneamento, associando-o principalmente ao serviço de coleta de resíduos sólidos, sendo este um fator limitante para análise de ISLU.

A criação de um plano municipal de gerenciamento de resíduos sólidos pode trazer grandes modificações ao cenário exposto, sendo revisto variáveis como rotas, frequência e abrangência de coleta, além do mapeamento e instalação de coletores e abrigos temporários para resíduos em pontos estratégicos dos bairros, minimizando a disposição inadequada e a dispersão de resíduos sólidos em locais públicos.

\section{Conclusão}

O Índice de Satisfação de Limpeza Urbana se apresenta como um importante parâmetro para averiguar o contentamento dos residentes quanto a qualidade do serviço público prestado. Sobretudo, com contínua expansão da malha urbana das cidades brasileiras. Dessa forma, as considerações atribuídas pelos moradores da zona urbana do município de Pau dos Ferros/RN no que diz respeito a coleta, transporte, condicionamento, descarte, destinação e disposição dos resíduos é indispensável, pois demonstra que a qualidade do serviço vai para além do seu fornecimento pelo poder público.

De acordo com os dados levantados com os residentes da zona urbana de Pau dos Ferros/RN, foi possível concluir que a satisfação com o sistema de limpeza urbana se apresenta predominantemente com indicadores que variam entre médio e baixo desempenho. Além disso, quanto a distribuição dos bairros mais bem avaliados, nesse caso com a classificação média, os mesmos apresentam uma espacialização que difere das principais zonas urbanas brasileira, na qual as áreas mais centrais acabam sendo mais assistidas pelo poder público, coisa que não foi possível verificar no município pertencente a esse estudo.

No entanto, vale ressaltar que a efetividade do serviço de limpeza urbana se concretiza mediante a participação dos residentes locais, sobretudo na disposição dos resíduos em locais adequados, contribuindo dessa forma para facilitar no recolhimento durante o período em que a coleta comum semanal estiver presente.

Dessa maneira, como forma de diminuir os impactos ocasionados, é de suma importância a adoção de melhorias no sistema de gerenciamento de resíduos sólidos presentes no município em questão, especialmente, podendo atender as diretrizes especificadas na PNRS, além da implementação de ações conjuntas entre o poder público, privado e instituições de ensino locais para o desenvolvimento de atividades voltadas para a educação ambiental dos residentes.

Participação dos autores: TTC - levantamento bibliográfico, coleta de dados primários, Coleta de dados secundários, redação do manuscrito; JMB - proposta do estudo, revisão conceitual e revisão do manuscrito; BMDM - proposta do estudo, revisão conceitual, preparação e revisão do manuscrito; ATAR, RSS - coleta de dados secundários, elaboração 
do manuscrito, confecção de materiais gráficos; ABQJ, FSR, SBN, HCGC - coleta de dados primários, coleta de dados secundários, elaboração do manuscrito.

Aprovação ética e licenças: Segundo a Resolução 510/ 2016, pesquisa de opinião pública com participantes não identificados está dispensada de registro no CEP/CONEP.

Disponibilidade dos dados: os dados não estão em bases de dados ou repositórios.

Fomento: Não existiu durante o estudo disponibilidade nenhum fomento.

Conflito de Interesses: Não há conflito de interesses.

\section{Referências}

Araújo KK, Pimentel AK. 2015. A problemática do descarte irregular dos resíduos sólidos urbanos nos bairros Vergel do Lago e Jatiúca em Maceió, Alagoas. Revista Gestão \& Sustentabilidade Ambiental, 4(2): 626-668. DOI: http://dx.doi. org/10.19177/rgsa.v4e22015626-668.

Barbosa JO, Moura GG. 2020. A relação de limpeza urbana e qualidade ambiental: um estudo sobre as condições de limpeza urbana no bairro Nova Ituiutaba I, na cidade de Ituiutaba/MG. Caminhos de Geografia, 21(73): 399-414. DOI: http://dx.doi.org/10.14393/rcg217348613.

Bezerra JA, Lima KQ. Desigualdades socioespaciais em pequenas cidades: a segregação residencial na cidade de Pau dos Ferros-RN. Revista Geotemas, Pau dos Ferros, RN, v. 1, n. 1, p. 43-54, 2011.

BRASIL. Secretaria Especial de Desenvolvimento Urbano da Presidência da República. Manual gerenciamento integrado de resíduos sólidos. IBAM, 2001.

Dantas, JRQ. As cidades médias no desenvolvimento regional: um estudo sobre Pau dos Ferros (RN). 2014. 260 f. Tese (Doutorado) - Curso de Ciências Sociais, Universidade Federal do Rio Grande do Norte, Natal, 2014.

Galdino SJ, Malysz ST. 2016. Os riscos ocupacionais dos garis coletores de resíduos sólidos urbanos. Revista Percurso, 8(2): 187-205.

IBGE - Instituto Brasileiro de Geografia e Estatística. 2019. Panorama: Pau dos Ferros. Diretoria de Pesquisas, Coordenação de População e Indicadores Sociais. Rio de Janeiro: IBGE. Disponível em: https://cidades.ibge.gov.br/ brasil/rn/pau-dos-ferros/panorama. Acesso em: 25 abr. 2020.

IBGE - Instituto Brasileiro de Geografia e Estatística. 2019. Panorama: Rio Parnaíba. Diretoria de Pesquisas, Coordenação de População e Indicadores Sociais. Rio de Janeiro: IBGE. Disponível em: https://cidades.ibge.gov.br/ brasil/mg/rio-paranaiba/panorama. Acesso: 21 set. 2020.

Maia, AAS. 2016. Cenário do Saneamento Básico no Município de Pau dos Ferros-RN (2015-2016). [Relatório de Estágio Supervisionado, curso de Administração]. Universidade do Estado do Rio Grande do Norte - UERN.

Marchi CMDF. 2015. Novas perspectivas na gestão do saneamento: apresentação de um modelo de destinação final de resíduos sólidos urbanos. Revista Brasileira de Gestão Urbana, 7(1): 91-105. DOI: https://www.redalyc.org/articulo. oa? id=193135340007.

Martins GA. 2008. Estatística geral e aplicada. 3a ed., São Paulo: Atlas, 424p.

Menezes Filho FCM, Rodrigues ALM. 2017. Avaliação do saneamento ambiental por meio da proposição e aplicação de índices de percepção e satisfação populacional. Holos Environment, 17(1): 122-137. DOI: http://dx.doi.org/10.14295/ holos.v17i1.12177.

Monteiro JHP. 2018. Manual de Gerenciamento de Resíduos Sólidos (IBAM). Cadernos da Rede, 1(1), 202-496. 
Mucelin CA, Bellini M. 2008. Lixo e impactos ambientais perceptíveis no ecossistema urbano. Sociedade \& natureza, 20(1), 111-124. DOI: https://doi.org/10.1590/S1982-45132008000100008.

Paiva FCS, Giesta LC. 2019. Gestão socioambiental em micro e pequenas indústrias de Pau dos Ferros-RN. Gestão \& Produção, 26(2). DOI: https://doi.org/10.1590/0104-530x2984-19.

Ramos NF, Gomes JC, Castilhos Jr AB, Gourdon, R. 2017. Desenvolvimento de ferramenta para diagnóstico ambiental de lixões de resíduos sólidos urbanos no Brasil. Engenharia Sanitária e Ambiental, 22(6): 1233-1241. DOI: https://doi. org/10.1590/s1413-41522017165817.

Santana TCS, Diniz DVM. 2019. Configuração espacial e uso dos espaços livres públicos em cidade de médio porte: o caso de Pau dos Ferros, RN, Brasil/Spatial configuration and use of public free space in a medium-sized city: the case of Pau dos Ferros, RN, Brazil. Brazilian Journal of Development, 5(8): 11189-11201. DOI: https://doi.org/10.34117/ bjdv5n8-004.

Silva AF, Medeiros AA. 2011. Revista Geotemas, 1(2): 53-67. DOI: https://doi.org/10.33237/geotemas.v1i2.141.

Silva FSB, Guerra EC, Dantas JRQ. 2016. Desvelando aspectos e lógicas da reprodução capitalista no espaço: um estudo no comércio de rua em Pau dos Ferros/RN. Revista de Desenvolvimento Econômico - RDE, 17(32): 788-814. DOI: http://dx.doi.org/10.21452/rde.v17i32.3995.

SNIS - Sistema Nacional de Informações sobre Saneamento. 2018. Diagnóstico do Manejo de Resíduos Sólidos Urbanos - 2016. Brasília: MCIDADES.SNSA.

Teixeira DA, Prado Filho JF, Santiago AF. 2018. Indicador de salubridade ambiental: variações da formulação e usos do indicador no Brasil. Engenharia Sanitária e Ambiental, 23(3): 543-556. DOI: http://dx.doi.org/10.1590/s141341522018170866.

Teixeira PTR, Souza JAR, Moreira DA, Viana AMS, Soares JMC. 2016. Influência da população flutuante no planejamento do sistema de limpeza urbana. Revista Engenharia na Agricultura, 24(6): 457-462. DOI: https://doi.org/10.13083/ reveng.v24ie6.672.

Silva KC, Rosas LSP, Oliveira SRN. 2018. Gestão de Resíduos Sólidos do Brasil evolução e desafios a caminho: Uma Revisão Integrativa. Scientia Amazônia, 7(2): 1-15. 